\title{
First case report of M1 macrophage polarization in an untreated symptomatic patient with toxoplasmosis
}

\author{
Graziano De Luca', Chiara Di Lisio ${ }^{1,2}$, Giuseppe Lattanzio³, Tommaso D'Antuono³, Marcella Liberatore ${ }^{3}$ \\ and Francesca Bianca Aiello ${ }^{2^{*}}$
}

\begin{abstract}
Background: In immunocompetent patients, acute toxoplasmosis is usually asymptomatic. We identified M1 macrophages in a case of symptomatic acute Toxoplasma gondii infection that resolved without treatment. M1 macrophages have been demonstrated in animal models of toxoplasmosis, but not in humans.

Case presentation: A 63-year-old woman presented with laterocervical and axillary bilateral lymphadenopathy. Her anamnesis defined an episode of high fever and prolonged asthenia 4 months previously, which suggested an infectious disease. Following laboratory, radiological, and pathological analyses, she was diagnosed with toxoplasmosis. Immunohistochemical analyses were performed on lymph node sections. More than $50 \%$ of the macrophages in the lymph node microgranulomas were $\mathrm{M} 1$ macrophages, defined by $\mathrm{CD} 68^{+} / \mathrm{p}-\mathrm{Stat} 1^{+}$staining, and the presence of Thelper 1 lymphocytes indicated an immune response known to induce M1 macrophage polarization. Activated endothelial cells were found only in inflamed areas. No therapy was administered before or after diagnosis, and the lymphadenopathy resolved after a follow-up of 5 months.
\end{abstract}

Conclusions: This is the first report to demonstrate the presence of M1 macrophages in human toxoplasmosis. Our findings contribute to the understanding of the pathogenesis of toxoplasmosis, and encourage further studies on the role of macrophage polarization in human toxoplasmosis.

Keywords: Toxoplasma gondii, Macrophage polarization, T helper 1 immune response, Immunodeficiency

\section{Background}

Toxoplasmosis is a parasitic infection that can be life threatening in immunodeficient patients and when it is transmitted congenitally. In immunocompetent patients, the acute infection is mostly asymptomatic, and is clinically evident in only $10 \%$ of cases, presenting as a flu-like illness associated with lymphadenopathy. It is frequently benign and patients usually recover, although, chorioretinitis, hepatitis, myocarditis, or encephalitis can sometimes develop. In other cases, the acute infection can result in chronic persistence of cysts within the tissues of the hosts, for which an effective immune response is important $[1,2]$.

\footnotetext{
*Correspondence: fbaiello@unich.it; francesca.aiello@unich.it 2Department of Medicine ad Aging Sciences, University G. d'Annunzio, Chieti-Pescara, via dei Vestini, 66100 Chieti, Italy

Full list of author information is available at the end of the article
}

Macrophage polarization has different effects that influence the progression of inflammatory responses. M1 macrophages are activated by Toll receptor ligands and cytokines produced by $\mathrm{T}$ helper 1 lymphocytes, and they sustain inflammation [1]. M2 macrophages are activated by various cytokines, including IL-4 produced by T helper II lymphocytes, and they show a wide spectrum of functions, including angiogenesis, immune suppression, and tissue remodeling and repair [1,3]. In vitro studies have suggested that a subset of M2 macrophages predominates during inflammation repair, and that a switch from one functional phenotype to another is possible in response to microenvironmental signals $[1,3]$.

Most studies that have focused on macrophage polarization have been performed in vitro or in animal models [1,3], and thus the characterization of macrophages in human diseases is an important issue. M1 
macrophages have been demonstrated in experimental models of Toxoplasma gondii (T. gondii) infection, although not in humans. Interferon gamma (IFN- $\gamma$ ) produced by $\mathrm{T}$ lymphocytes is the major mediator of resistance against $T$. gondii [4]. Activation of the transcription factor signal transducer and activator of transcription 1 (Stat1) is essential to mediate the antimicrobial effects of IFN- $\gamma$, particularly in the immune response against $T$. gondii [2]. Stat1-deficient mice are indeed highly susceptible to this disease [2]. In macrophages, IFN- $\gamma$ induces Stat1 phosphorylation, dimerization and translocation to the nucleus, where it leads to the transcription of genes encoding proteins that are essential for the response to intracellular parasites (inducible nitric oxide synthase, also called iNOS, immunity-related GTPase and others) [2]. Combined immunoreactivity for nuclear phospho-Stat1 (p-Stat1) and the membrane macrophage CD68 marker has been shown to identify M1 macrophages in human tissues [5]. The CD68 antigen, which is specifically recognized by the PG-M1 monoclonal antibody, is considered the most specific marker available for all human macrophages [6, 7], thus a double CD68/p-Stat1 positivity clearly allows an accurate detection of the M1 macrophage subset. Using this method we identified M1 macrophages in a human T. gondii infection. Moreover, we observed CD31positive endothelial cells with nuclear p-Stat1 immunoreactivity in areas with mononuclear cell infiltration, which suggests inflammation-induced endothelial cell activation.

\section{Case presentation}

A 63-year-old nulliparous woman underwent mammary and axillary echography for breast cancer screening in January 2016. No lesions were detected in the mammary glands. However, a bilateral axillary lymphadenopathy was observed. Physical examination showed bilateral tumefaction of both axillary and laterocervical nodes. In February 2016 she underwent hematological counseling to exclude lymphoproliferative diseases. Her medical history revealed an episode of high fever that had lasted 1 week and a prolonged asthenia. This had occurred at the end of August 2015, and suggested an infectious disease. Her blood count showed lymphocytosis (3340 cells/ $\left.\mathrm{mm}^{3}, 43 \%\right)$. Cytomegalovirus, Epstein Barr virus, human immunodeficiency virus, and human herpes virus $1 / 2$ serological tests were negative. The anti-T. gondii IgM index was 0.80 , slightly positive $(>0.60)$, and the IgG titer was $1448 \mathrm{UI} / \mathrm{ml}$, considerably high, pointing to an acute $T$. gondii infection [8]. Computed tomography scan and, after a month, a surgical biopsy were performed which excluded lymphoid or epithelial tumors. Bilateral hilar and mediastinal lymphadenopathy were observed. Histological evaluation of the axillary lymph-nodes showed alterations of the normal architecture with marked follicular hyperplasia and many micro-granulomas composed of epithelioid histiocytes with abundant pale cytoplasm, encroaching on the mantle zone and germinal centers (Fig. 1a), and monocytoid B-cell hyperplasia enlarging the nodal sinuses. The triad of follicular hyperplasia, micro-granulomas, and monocytoid B-cell hyperplasia is considered highly specific for T. gondii infection [9]. Clinical, serological and histopathological findings thus revealed the late phase of an acute T. gondii infection. No therapy was administered before or after biopsy. The lymphadenopathy resolved after a follow-up of 5 months, and thus, the infection was self-limited. Immunohistochemistry was performed on lymph node sections (2-3 sections/staining). Murine anti-CD68-CD3,-CD4,-CD8,-CD20, and -CD31 monoclonal antibodies (clones PG-M1, F7.2.38, 4B12, C8/144, L26 and JC70A, respectively) were used alone or in combination with a rabbit-anti-p-Stat1 monoclonal antibody (clone 58D6). Murine anti-iNOS monoclonal antibody (clone 4E5) and rabbit anti-IFN- $\gamma$ polyclonal antibody were used alone to detect iNOS and IFN- $\gamma$ immunoreactivity. For single red color staining after antigen retrieval ( $\mathrm{pH} 6$ or $\mathrm{pH} 9$ as appropriate) sections were incubated with the primary antibody for $1 \mathrm{~h}$ at room temperature and then with a biotinylated rabbit antimouse secondary antibody (30 $\mathrm{min})$ and streptavidin alkaline phosphatase (30 min). Alkaline phosphatase was visualized by incubation with Vulcan Fast Red (10 min). The staining was performed using the automated Omnis immunostainer (Dako, Glostrup, Denmark). For single brown color staining, after antigen retrieval sections were incubated with the primary antibody for $1 \mathrm{~h}$, or overnight at room temperature, and then stained by the Envision technique (Dako). The staining was performed using the automated Autostainer Link 48 immunostainer (Dako) The single red and the single brown color stainings were performed sequentially for double staining. Cells were counted in 10 randomly selected high power fields (HPFs), with, numbers per HPF expressed as mean \pm standard deviation.

To investigate whether M1 macrophages were involved in the inflammatory reaction lymph node sections were double stained with antibodies recognizing nuclear pStat1 and the membrane macrophage marker CD68 (Fig. 1b, c). In microgranulomas the mean number of $\mathrm{CD}^{+} 8^{+}$macrophages was $61.7 \pm 24.3$ per HPF. The mean numbers of $\mathrm{CD}^{+} 8^{+} \mathrm{pStat}^{+}$and $\mathrm{CD} 68^{+} \mathrm{p}$-Stat $1^{-}$ macrophages were $37.5 \pm 22$ and $28.2 \pm 13$ per HPF, respectively. The mean numbers of CD3-, CD4- and CD8positive T-lymphocytes were $308.7 \pm 139.5$; $269.7 \pm 130.9$ and $120.3 \pm 51.6$ per HPF, respectively. Among the microgranulomas, a small number of $\mathrm{p}-\mathrm{Stat} 1^{+} / \mathrm{CD} 68^{-}$ mononuclear cells were present (Fig. 1b) $(48.1 \pm 26$ per HPF). CD3/p-Stat1 double staining confirmed the presence of p-Stat $1^{+} \mathrm{T}$ lymphocytes in these areas $(13.5 \pm 5.3$ per HPF). A subset of the p-Stat $1^{+}$cells were $\mathrm{CD}^{+}(6.8 \pm 2.9$ per HPF) (Fig. 1d). We did not assess the number of 

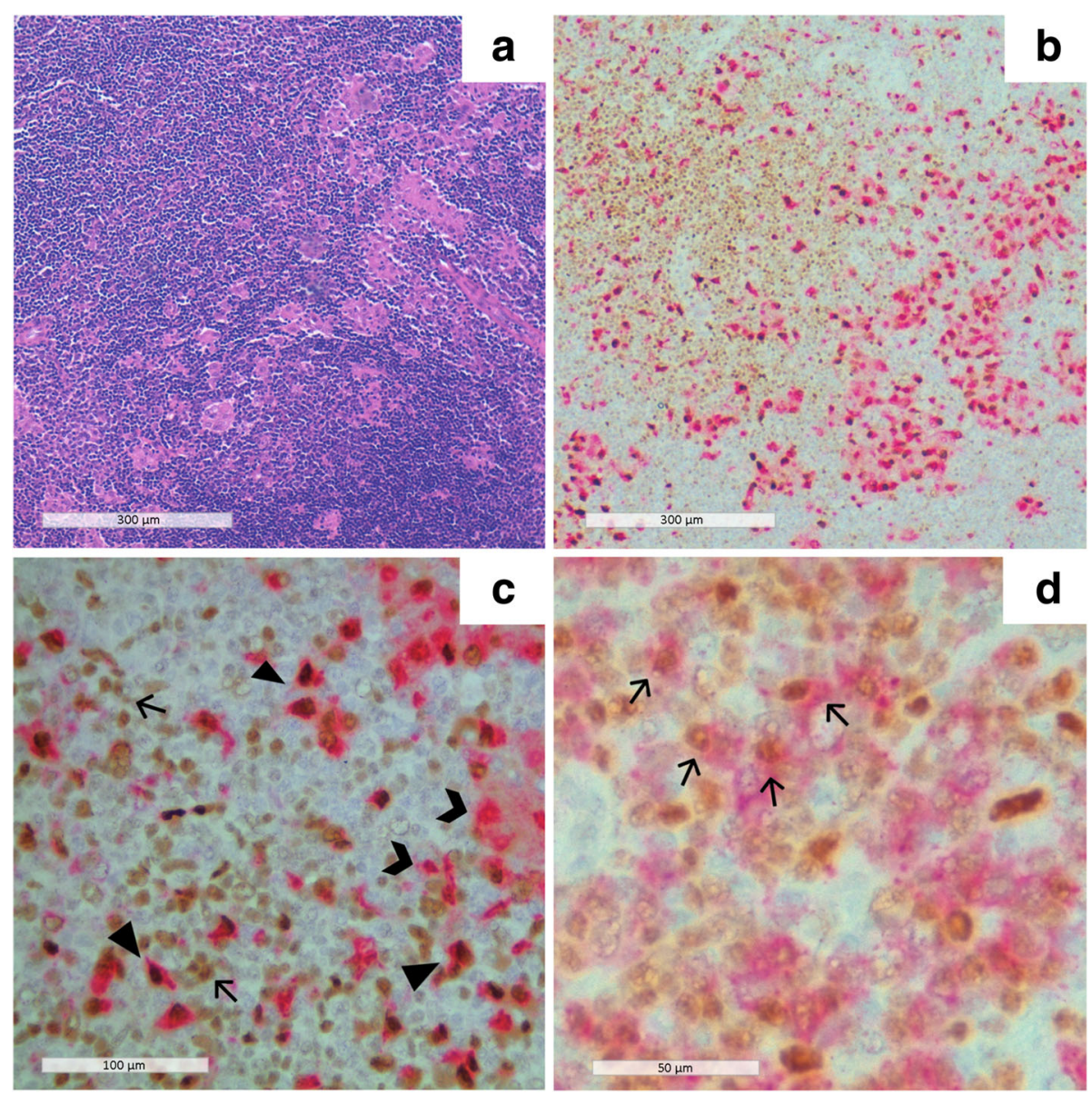

Fig. 1 Morphological and immunohistochemical evaluation of inflammatory cells in axillary lymph nodes. a hematoxylin-eosin: scattered microgranulomas; b CD68 /pStat1 immunoreactivity: CD68+, pStat1+ and CD68/pStat1+ cells (CD68: red color, pStat1: brown color); c CD68/pStat1 double immunoreactivity: triangles, CD68 single immunoreactivity: guillemets, pStat1+ single immunoreactivity: arrows (CD68: red color, pStat1: brown color); d CD8/pStat1 immunoreactivity, arrows indicate /pStat1+ cells (CD8: red color, pStat1: brown color)

p-Stat $1^{+} / \mathrm{CD} 4^{+}$cells because the intensity of the membrane positivity was low when the anti-CD4 antibody was used in double staining. $\mathrm{CD} 20^{+}$B lymphocytes were p-Stat1 negative (data not shown). Scattered IFN- $\gamma^{+}$mononuclear cells were observed between microgranulomas and in germinal centers (Fig. 2a). In these areas iNOS ${ }^{+}$mononuclear cells were present ( $36.4 \pm 14.9$ per HPF) (Fig. $2 b$ ).

$\mathrm{CD}^{+} 1^{+}$endothelial cells showed a marked nuclear pStat 1 immunoreactivity only in areas where $\mathrm{p}$-Stat $1^{+}$ mononuclear cells were present (Fig. 3a), whereas, in the absence of $\mathrm{p}$-Stat $1^{+}$infiltrate, they were negative or very weakly positive (Fig. 3b).

\section{Discussion and conclusions}

We found that in a human $T$. gondii infection more than $50 \%$ of the macrophages in microgranulomas were polarized as M1 macrophages during the IgM seroreversion/IgG seroconversion, which corresponds to the late phase of the inflammatory response. In this phase, a small percentage of
T-lymphocytes were p-Stat1 immunoreactive. In addition, IFN- $\gamma$ and iNOS immunoreactive cells showed a similar localization. Our observations suggest that in the acute phase of the anti-T. gondii immune response $T$ helper 1 lymphocytes produced IFN- $\gamma$ stimulating the activation of the p-Stat1 driven antimicrobial pathways in macrophages.

In mice, $T$. gondii replication in brain endothelial cells precedes invasion of the central nervous system [10]. Importantly, in vitro data have shown that cytokine-activated murine endothelium contributes to the clearance of $T$. gondii through recruitment of $\mathrm{CD}^{+}$lymphocytes [11]. We observed human endothelial cells that expressed pStat1 in inflamed areas, where pStat- $1^{+}$mononuclear cells were present. It is tempting to speculate that human activated endothelial cells contribute to the anti- $T$. gondii immune response. In the present patient the infection self-resolved, which suggested that the M1 response led to healing and might have a major role in promoting an effective response. Recent results in animal models indicate 


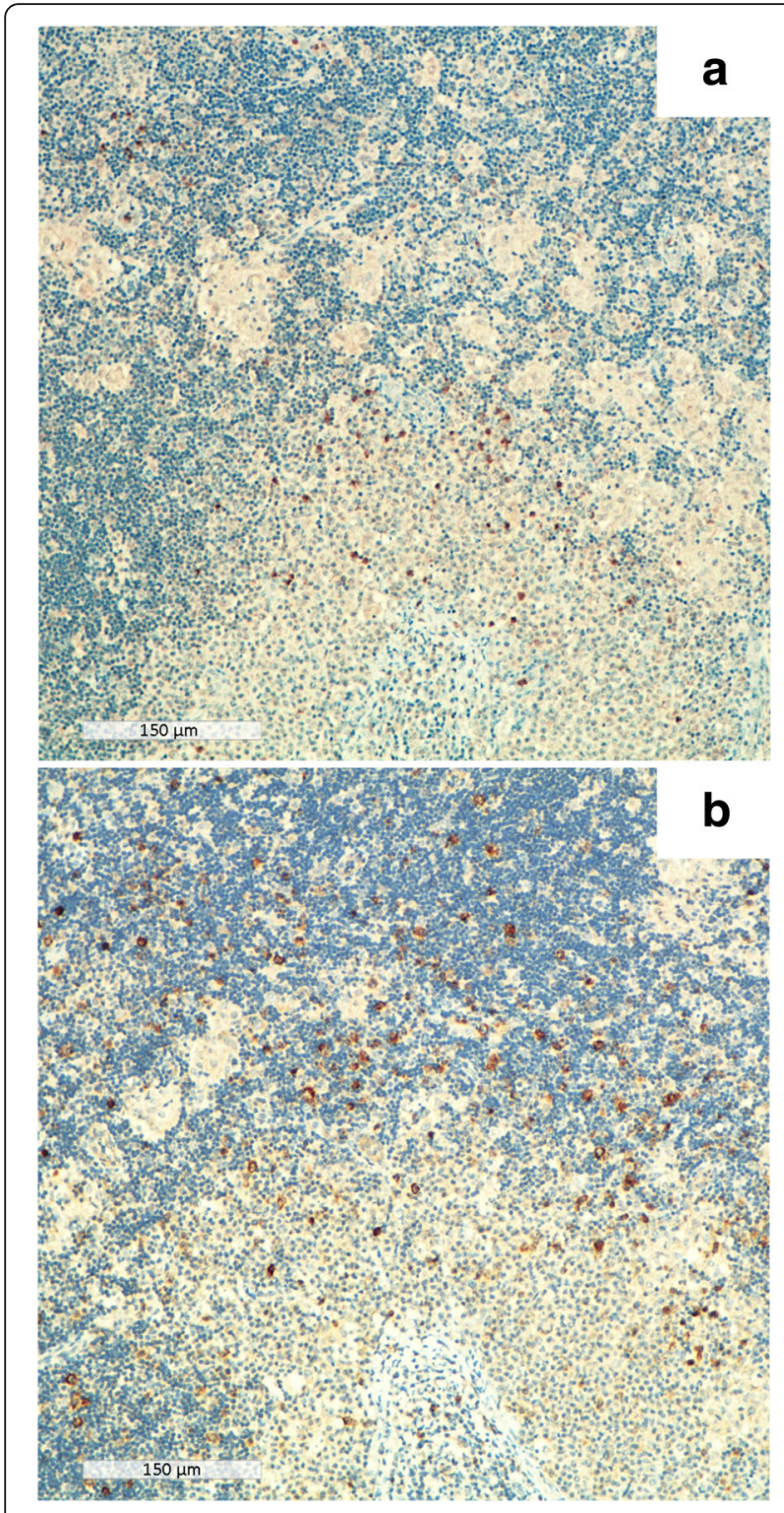

Fig. 2 Immunohistochemical evaluation of IFN- $\gamma$ and iNOS immunoreactive cells in axillary lymph nodes. a Scattered IFN- $\gamma$ positive mononuclear cells between microgranulomas and in germinal centers; b Numerous iNOS positive mononuclear cells between microgranulomas and in germinal centers

that M2 macrophage polarization in T. gondii infection may be deleterious and be associated with chronic persistence [12].

Although our findings concern a single patient and cannot be generalized, they encourage studies about the role of macrophage polarization in toxoplasma chronic persistence and reactivation in human subjects.

Primary T. gondii infection in pregnancy is treated with spiramycin alone or in combination with other drugs, and the pooled rate of vertical transmission in treated patients after therapy is about $10 \%$ [13]. Anti-parasitic treatment
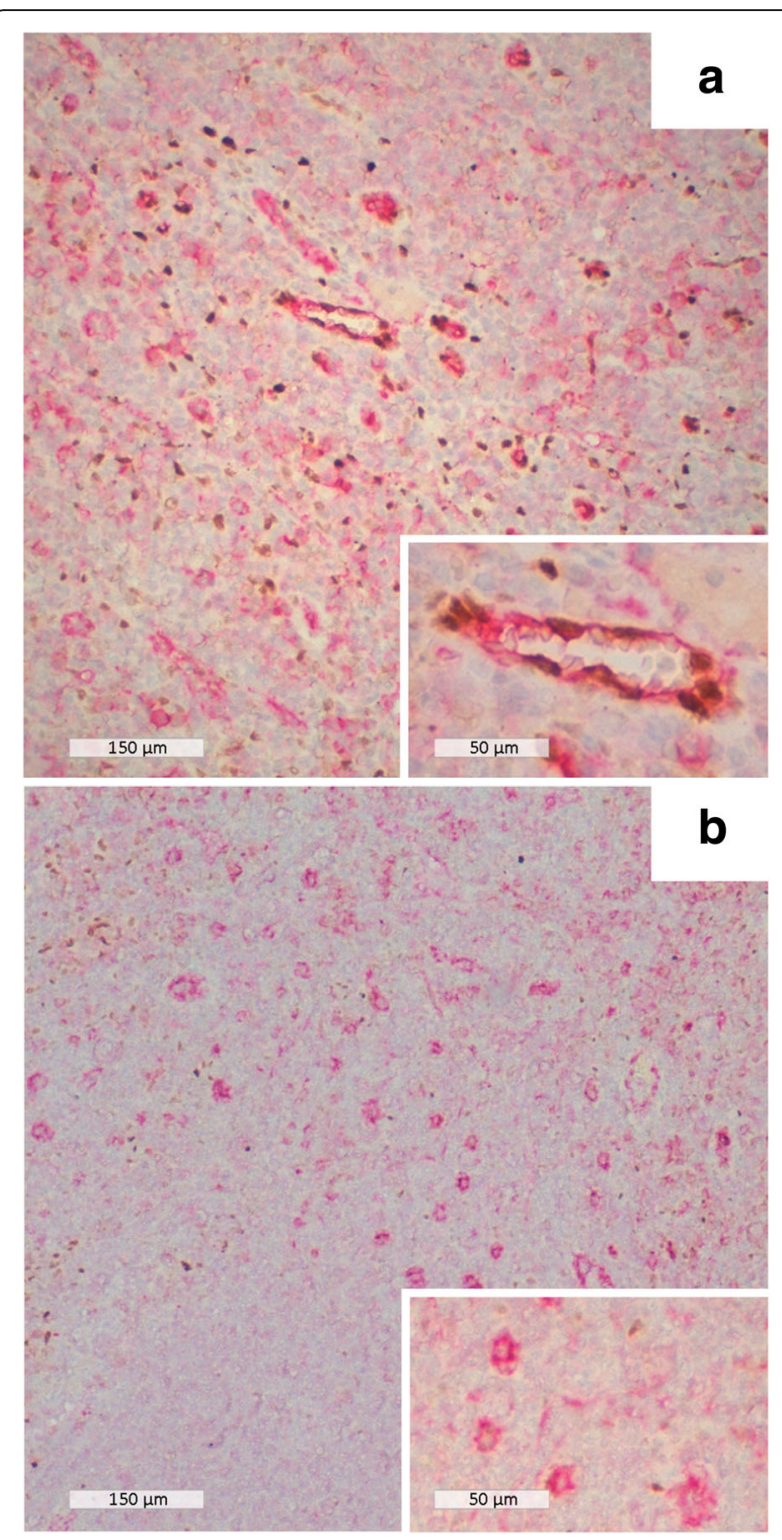

Fig. 3 Immunohistochemical evaluation of endothelial cells in axillary lymph nodes. a endothelial cell CD31/pStat1 immunoreactivity in inflamed areas (CD68: red color, pStat1: brown color); $\mathbf{b}$ endothelial cell CD31/pStat1 immunoreactivity in areas without mononuclear cell infiltration. Insets in panel $\mathbf{a}$ and $\mathbf{b}$ show CD31/pStat1 immunoreactivity of endothelial cell at higher magnification

suppresses the production of specific IgM and IgG in mice [14] and decreases the production of IgG in pregnant women [15]. Whether anti-parasitic therapy affects macrophage polarization remains to be investigated. To date, all studies concerning macrophage polarization in toxoplasmosis have been performed in experimental animal models. We identified for the first time a large number of M1 macrophages in a symptomatic case of human toxoplasmosis that spontaneously resolved. 


\section{Abbreviations}

IFN- $\gamma$ : Interferon gamma; iNOS: Inducible nitric oxide synthase; pStat1: Phosphosignal transducer and activator of transcription 1; Stat1: Signal transducer and activator of transcription 1; T. gondii: Toxoplasma gondii

\section{Acknowledgments}

We thank Drs. Fiorella Calabrese and Manuela lezzi for providing anti-iNOS and IFN- $\gamma$ antibodies, respectively, and Dr. Antonio Sisto for critical review of the manuscript.

\section{Funding}

Supported by funds from Ministero dell'Istruzione, dell'Università e della Ricerca, Italy. The funders had no role in the study design, data collection and analysis, decision to publish or preparation of the manuscript.

\section{Availability of data and materials}

The datasets used/and or analysed in this study are available from the corresponding authors on reasonable request.

\section{Authors' contributions}

All authors contributed to design the study. Acquisition, analysis and interpretation of data: GDL, CDL, GL. Immunohistochemical analyses: TD'A, ML. GDL and FBA wrote the manuscript. All authors have read and approved the manuscript.

\section{Ethics approval and consent to participate}

The study has been approved by the authors' institutional review board (Comitato Etico delle Province di Chieti e Pescara).

\section{Consent for publication}

Written informed consent from the patient was obtained.

\section{Competing interests}

The authors have no competing interests to declare.

\section{Publisher's Note}

Springer Nature remains neutral with regard to jurisdictional claims in published maps and institutional affiliations.

\section{Author details}

${ }^{1}$ Center for Excellence on Aging and Translational Medicine, University G. d'Annunzio, Chieti-Pescara, via dei Vestini, 66100 Chieti, Italy. ${ }^{2}$ Department of Medicine ad Aging Sciences, University G. d'Annunzio, Chieti-Pescara, via dei Vestini, 66100 Chieti, Italy. ${ }^{3}$ Department of Oncology, ASL2, SS Annunziata Hospital, via dei Vestini, 66100 Chieti, Italy.

Received: 6 October 2017 Accepted: 19 March 2018

Published online: 27 March 2018

\section{References}

1. Murray PJ, Wynn TA. Protective and pathogenic functions of macrophage subsets. Nat Rev Immunol. 2011;11:723-37. https://doi.org/10.1038/nri3073.

2. Sturge $C R$, Yarovinsky F. Complex immune cell interplay in the gamma interferon response during toxoplasma gondii infection. Infect Immun. 2014; 82:3090-7. https://doi.org/10.1128/IAl.01722-14.

3. Lichtnekert J, Kawakami T, Parks WC, Duffield JS. Changes in macrophage phenotype as the immune response evolves. Curr Opin Pharmacol. 2014; 13(4):555-64. https://doi.org/10.1016/j.coph.2013.05.013.

4. Suzuki Y, Orellana MA, Schreiber RD, Remington JS. Interferon-gamma: the major mediator of resistance against toxoplasma gondii. Science. 1988;240: 516-8. PMID: 3128869

5. Barros MHM, Hauck F, Dreyer JH, Kempkes B, Niedobitek G. Macrophage polarisation: an immunohistochemical approach for identifying M1 and M2 macrophages. PLoS One. 2013;8:e80908. https://doi.org/10.1371/journal. pone.0080908

6. Falini B, Flenghi L, Pileri S, Gambacorta M, Bigerna B, Durkop H, Eitelbach F, Thiele J, Pacini R, Cavaliere A, et al. PG-M1: a new monoclonal antibody directed against a fixative-resistant epitope on the macrophage-restricted form of the CD68 molecule. Am J Pathol. 1993;5:1359-72.
7. Groisman GM, Schafer I, Amar M, Sabo E. Expression of the histiocytic marker PG-M1 in granuloma annulare and rheumatoid nodules of the skin. J Cutan Pathol. 2002;10:590-5.

8. Fritsche TR, Selvarangan R. Medical parasitology. In: McPherson RA, Pincus MR, editors. Henry's clinical diagnosis and management by laboratory methods. 22nd ed. Philadelphia: Elsevier Saunders; 2011. p. 1188-238.

9. Miranda RN, Khoury JD, Medeiros LJ. Toxoplasma lymphadenitis. In: Cheng $L$, editor. Atlas of lymph node pathology. 1st ed. New York: Springer Science; 2013. p. 49-52.

10. Konradt C, Ueno N, Christian DA, Delong JH, Pritchard GH, Herz J, Bzik DJ, Koshy AA, McGavern DB, Lodoen MB, Hunter CA. Endothelial cells are a replicative niche for entry of toxoplasma gondii to the central nervous system. Nat Microbiol. 2016;1:16001. https://doi.org/10.1038/nmicrobiol.2016.1.

11. Wang X, Michie SA, Xu B, Suzuki Y. Importance of IFN-gamma-mediated expression of endothelial VCAM-1 on recruitment of CD8+ T cells into the brain during chronic infection with toxoplasma gondii. J Interf Cytokine Res. 2007:4:329-38. https://doi.org/10.1089/jir.2006.0154.

12. Zhang Q, He L, Kong L, et al. Genotype-associated arginase 1 expression in rat peritoneal macrophages induced by toxoplasma gondii. J Parasitol. 2015: 418-23. https://doi.org/10.1645/14-696.1.

13. Wei HX, Wei SS, Lindsay DS, Peng HJ. A systematic review and meta-analysis of the efficacy of anti-toxoplasma gondii medicines in humans. PLoS One 2015:e0138204. https://doi.org/10.1371/journal.pone.0138204. eCollection 2015.

14. Alvarado-Esquivel C, Niewiadomski A, Schweickert B, Liesenfeld O. Antiparasitic treatment suppresses production and avidity of toxoplasma gondii-specific antibodies in a murine model of acute infection. Eur J Microbiol Immunol. 2011;1:249-55. https://doi.org/10.1556/EuJMI.1.2011.3.9.

15. Meroni V, Genco F, Tinelli C, Lanzarini P, Bollani L, Stronati M, Petersen E. Spiramycin treatment of toxoplasma gondii infection in pregnant women impairs the production and the avidity maturation of T. Gondii-specific immunoglobulin G antibodies. Clin Vaccine Immunol. 2009:1517-20. https://doi.org/10.1128/CVI.00253-09.

\section{Submit your next manuscript to BioMed Central and we will help you at every step:}

- We accept pre-submission inquiries

- Our selector tool helps you to find the most relevant journal

- We provide round the clock customer support

- Convenient online submission

- Thorough peer review

- Inclusion in PubMed and all major indexing services

- Maximum visibility for your research

Submit your manuscript at www.biomedcentral.com/submit
Biomed Central 